
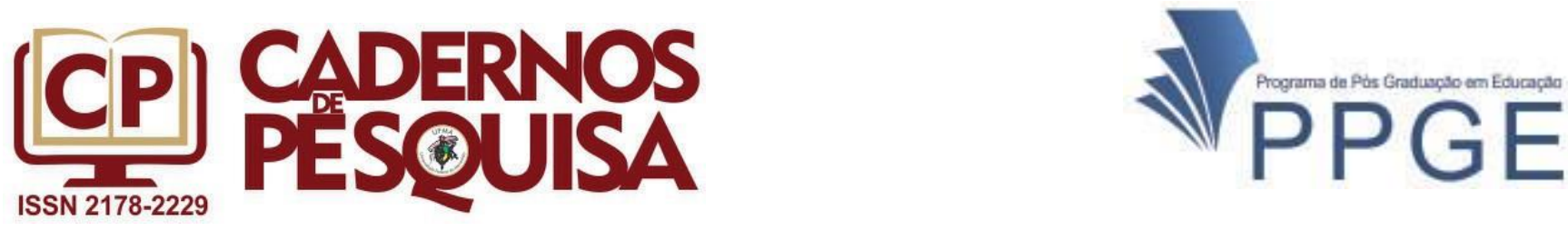

\title{
Concepções atribuídas ao corpo pelas professoras do primeiro ano do Ensino Fundamental
}

\author{
Conceptions attributed to the body by the teachers of the \\ first year of Fundamental Education
}

\section{Concepciones atribuidas al cuerpo por las profesoras del primer año de la Enseñanza Fundamental}

\author{
Margareth Rocha Lima Matos ${ }^{1}$ \\ ORCID: http://orcid.org/0000-0001-6194-7482 \\ Nilma Margarida de Castro Crusoé ${ }^{2}$ \\ ORCID: http://orcid.org/0000-0002-0610-8237
}

\begin{abstract}
Resumo: Este estudo se insere nas discussões sobre corpo, no primeiro ano do Ensino Fundamental, mais especificamente, sobre concepções de corpo, pelas professoras dessa fase escolar. Utilizou-se para a realização dessa pesquisa uma abordagem qualitativa/interpretativa. $O$ campo empírico deste estudo é uma escola do Ensino Fundamental, de uma cidade do interior da Bahia. Foram entrevistadas 5 (cinco) professoras, responsáveis pelas cinco turmas existentes. Utilizou-se a entrevista semi-estruturada e a análise de conteúdo para análise dos dados. Os resultados indicaram que o corpo é reconhecido como importante, para essas educadoras. A dimensão do cuidado com a saúde e a estética, foram elementos fortes na concepção bem como, sua relação e interferência na aprendizagem.
\end{abstract}

Palavras-chave: Corpo. Ensino Fundamental. Professoras.

\footnotetext{
${ }^{1}$ Mestre em Educação pelo Programa de Pós-Graduação em Educação (PPGEd/UESB). Professora da Educação Básica do Estado da Bahia- SEC/BA. Professora de Práticas Integradoras, Educação Física e Educação Desportiva no Ensino Médio. Professora das disciplinas: Projeto Integrador em Educação Física e Lazer e Recreação no curso de Bacharelado em Educação Física da Faculdade de Tecnologia e Ciências- FTC/VIC. E-mail: margorlmatos@yahoo.com.br

${ }^{2}$ Professora Plena da Universidade Estadual do Sudoeste da Bahia- UESB. Doutora em Educação em Educação, pela Universidade Federal do Rio Grande do Norte (UFRN). Autora do livro Interdisciplinaridade: representações sociais de professores de matemática e Prática pedagógica interdisciplinar na escola fundamental: sentidos de professoras. Professora de do Programa de Mestrado em Educação (PPGEd/Uesb).; Líder do Grupo de Estudo e Pesquisas em Práticas Curriculares e Educativas (GEPPCE) e membro do Comitê Editorial da Revista Práxis Educacional, do Programa de Mestrado em Educação (PPGEd/Uesb). Atua, principalmente, nos seguintes temas: Representação Social, Prática pedagógica e Prática educativa; Fenomenologia das Relações Sociais. É co-autora em capítulos no livro Manual de Investigação Qualitativa em Educação, Livro Premiado como BEST BOOK IN SPANISH OR PORTUGUESE CONTRIBUITION TO QUALITATIVE INQUIRY 2016, pelo Committee for theBiannual Book in Spanish orPortuguese ICQI Award, Universidad Autónoma Metropólitana- Xochimilco. E-mail: nilcrusoe@gmail.com
} 
Abstract: This study is part of the discussions about the body, in the first year of elementary school, more specifically, about body conceptions, by the teachers of that school stage. A qualitative / interpretative approach was used to carry out this research. The empirical field of this study is a primary school in a city in the interior of Bahia. Five (5) teachers were interviewed, responsible for the five existing classes. Semi-structured interviews and content analysis were used for data analysis. The results indicated that the body is recognized as important for these educators. The dimension of health care and aesthetics were strong elements in conception as well as their relation and interference in learning.

Key words: Body. Elementary School. Teachers.

Resumen: Este estudio se inserta en las discusiones sobre el cuerpo, en el primer año de la Enseñanza Fundamental, más específicamente, sobre concepciones de cuerpo, por las profesoras de esa fase escolar. Se utilizó para la realización de esta investigación un abordaje cualitativo / interpretativo. El campo empírico de este estudio es una escuela de la Enseñanza Fundamental, de una ciudad del interior de Bahía. Se entrevistaron 5 (cinco) profesoras, responsables de las cinco clases existentes. Se utilizaron entrevistas semiestructuradas y análisis de contenido para el análisis de datos. Los resultados indicaron que el cuerpo es reconocido como importante, para esas educadoras. La dimensión del cuidado con la salud y la estética, fueron elementos fuertes en la concepción así como, su relación e interferencia en el aprendizaje.

Palabras clave: Cuerpo. Enseñanza fundamental. Maestros.

\section{INTRODUÇÃO}

O tema se insere nas discussões sobre o corpo na escola, como lidar com o corpo das crianças como um corpo social marcado por questões de gênero, classe e etnia. Entende-se que trabalhar tais diferenças, no espaço escolar, é urgente e necessário, pois ainda percebemos que esse tema é tratado como tabu em sala de aula, seja pelo "desconhecimento" das discussões sobre produção social do corpo; seja pelo preconceito, o que torna a questão ainda mais preocupante; seja pelo fato de que

O corpo parece ter ficado fora da escola. Essa é, usualmente, a primeira impressão quando observamos as mais consagradas teorias educacionais ou os cursos de preparação docente. E talvez não nos surpreendamos com isso, já que nossa formação no contexto filosófico do dualismo ocidental leva-nos a operar, em princípio, com a noção de uma separação entre corpo e mente. Importante teórica negra feminista, bel! hooks lembra-nos de tal dicotomia, afirmando que, por isso, nós, professoras e professores, entramos numa sala de aula como se apenas a mente estivesse presente, como se fôssemos, todas, "espíritos descorporificados". (HOOKS, 1999, p. 115 apud LOURO, p. 2, 2000).

Ainda hoje se pratica a pedagogia da hemogeinização dos corpos e com isso, o quase desaparecimento deles em nome de uma formação cognitiva, negando-se

a possibilidade de considerar os diferentes corpos sociais, que se apresentam em sala de aula, como forma de ser e estar no mundo. Contudo,

[...] a história da educação nos mostra que tudo isso está muito longe da verdade: a preocupação com o corpo sempre foi central no engendramento dos processos, das estratégias e das práticas pedagógicas. 
disciplinamento dos corpos acompanhou, historicamente, o disciplinamento das mentes. Todos os processos de escolarização sempre estiveram - e ainda estão - preocupados em vigiar, controlar, modelar, corrigir, construir os corpos de meninos e meninas, de jovens homens e mulheres. (LOURO, p. 2, 2000).

A preocupação com o disciplinamento dos corpos, fruto de pesquisas sobre práticas pedagógicas nos anos iniciais ${ }^{3}$, deram origem ao tema de dissertação se mestrado cujo objetivo foi analisar concepções atribuídas ao corpo, pelas professoras do primeiro ano do Ensino Fundamental (EF). Escolheu-se o primeiro ano do EF, pelo fato de sua ampliação para nove anos ter como consequência a inserção da criança de seis anos de idade, em um contexto com alto grau de disciplinamento dos corpos e da mente, com pouco espaço para uma organização e disposição dos corpos, em sala de aula, que considere identidades diversas.

Com as Leis Federais no. 11.114/05 - que instituiu a obrigatoriedade da inserção da criança de seis anos de idade no EF-e a de nำ11.274/06 - que ampliou a duração do EF para nove anos, mantido o início aos 6 anos.

Pensar sobre a infância na escola e na sala de aula é um grande desafio para o ensino fundamental que, ao longo de sua história, não tem considerado o corpo, o universo lúdico, os jogos e as brincadeiras como prioridade. Infelizmente, quando as crianças chegam a essa etapa de ensino, é comum ouvir a frase "Agora a brincadeira acabou!". (BRASIL, 2007, p. 30).

É sobre essa ruptura na relação corpo/movimento corporal, da criança de seis anos ao ingressar no EF, que este trabalho norteia-se, pois enquanto na Educação Infantil (EI) o corpo tem assento, a organização dos tempos e espaços escolares atendem às necessidades (particularidades) da criança, no que tange a aprender e a brincar, no EF há ainda, uma separação entre corpo e mente.

No Brasil, o direito à educação na infância data da Constituição Federal de 1988. Institui-se o direito à educação, às crianças de zero a seis anos, como dever do Estado de oferecer creches e pré-escolas (Cap. III, art. 208, inciso IV). Passouse, então, a definir a El como primeira etapa da Educação Básica (EB). A Lei de Diretrizes e Bases da Educação, LDB 9394/1996, referenda os níveis escolares e coloca a EI na EB, (Art. 21). A creche e a pré-escola passam a ser integrados ao sistema educacional.

\footnotetext{
3 Pesquisas desenvolvidas no âmbito do Projeto "A organização da prática pedagógica dos professores dos três anos iniciais do Ensino Fundamental de nove anos: articulação e continuidade da trajetória escolar, cadastrado no Grupo de Estudo e Pesquisas em Prática Curricular e Educativa (GEPPCE), CNPq.
} 
A passagem de um programa a uma política efetiva, se concretizou no sequenciamento de ações para um novo ordenamento jurídico nas duas primeiras etapas da EB (EI e EF), além de diretrizes administrativas e pedagógicas a serem redesenhadas pelos sistemas educacionais, implantadas em escolas públicas e privadas brasileiras. Após o Plano Nacional de Educação (PNE), a inclusão da criança de seis anos pode ser percebida a partir de 2004 (Parecer no 24 de 15/09/2004). A Câmara de Educação Básica (CEB), do Conselho Nacional de Educação (CNE), estabeleceu pronunciamentos sobre o assunto, o que gerou uma série de Pareceres e Resoluções que conferiram lastro político e favoreceram a regulamentação das Leis 11.114/05 e 11.274/2006 (SILVA, 2010).

A Lei 11.274/06 altera os Artigos 29, 30 e 32 da LDB. No art. 29, determina-se a idade de seis para cinco anos da primeira etapa da Educação Básica, a Educação Infantil; esse artigo discorre sobre desenvolvimento integral da criança, em seu aspecto físico, psicológico, intelectual e social, completando a ação da família e da comunidade. O Art.30 determina que a educação infantil seja oferecida em creches, ou equivalente, para crianças de até três anos de idade; pré-escola, para crianças de quatro e cinco anos de idade, não mais até seis anos. No Artigo 32, o EF torna-se obrigatório, com duração, agora, de 9 (nove) anos, gratuito na escola pública, iniciando-se aos 6 (seis) anos de idade.

A partir desse novo ordenamento administrativo, faz-se necessário aliar a ampliação do EF a uma nova estrutura organizacional escolar que leve em consideração as especificidades da criança de seis anos, exigindo assim um redimensionamento da ação pedagógica no interior da escola. Surge, também, a necessidade de organizar as turmas observando a idade e o desenvolvimento das crianças, de prever e prover os recursos didáticos para esse fim e assegurar a formação continuada a todos, principalmente, à equipe pedagógica.

A ampliação do EF, de acordo com a legislação, é motivada pelas desigualdades existentes no país: um número elevado de crianças fora da escola e problemas de repetência e evasão escolar. A entrada mais cedo na escola é uma tentativa de minimizar essas desigualdades, pois pressupõe-se que ao entrem mais cedo na escola, as crianças têm menos dificuldades em relação ao ensino e a aprendizagem, devido ao contato maior com os códigos elaborados - educação 
formal. Essa assertiva trouxe certo consenso para a ampliação do ensino fundamental e inserção da criança de seis anos. (OLIVEIRA, 2010).

Observou-se que as crianças de seis anos, das classes média e alta, já estavam matriculadas em escolas e que, portanto, seria necessário incluir as crianças das classes desfavorecidas, também, numa tentativa de equidade educacional. A consideração de que as crianças de seis anos ainda estavam fora da escola, seja pela não obrigatoriedade ou por não existir oferta de vagas suficientes na educação infantil pública, gerou um aparente consenso de que o EF de nove anos implica em garantir um maior número de alunos matriculados nas escolas brasileiras e, portanto, assegurar a elas a efetivação do seu direito à educação (SILVA, 2010).

Muitos dos desafios da ampliação do EF de nove anos, ainda segundo os documentos oficiais, referem-se a acesso, permanência na escola, maior convívio escolar e qualidade do ensino. Esses desafios associados às singularidades da criança implicam em o quê ensinar (currículo), como ensinar (metodologias) e porque ensinar (projeto político pedagógico), princípios tais que servem como questões recorrentes e,

[...] frente a essa nova situação, é preciso se atentar à necessidade de equilibrar o tempo maior de convívio escolar e o respeito aos ciclos de desenvolvimento humano, particularmente na infância, conforme estabelecem as orientações para a inclusão das crianças de 6 anos. (SILVA, 2010, p.98).

Os limites regulatórios que subsidiaram a política desde 2005 anunciaram uma linha divisória entre a organização de oito para nove anos, não como mera inserção da criança de seis anos e sim com atenção especial à infância; as próprias leis revelam um esforço nesse sentido. Para isso, é preciso pensar nos tempos e espaços destinados a essa criança para que a entrada mais cedo não

[...] se limite à compreensão de um ano a mais, mas sim associada a ajustes mais amplos, para que não tenhamos "mais do mesmo", inclusive para os sistemas educacionais. A inserção da criança nessa idade estimulou um debate acerca das vantagens e ameaças que envolvem a antecipação da escolarização para elas. (SILVA, 2010, p.96).

Ainda segundo a autora, é admirável - e ao mesmo tempo preocupante - a rapidez com que os sistemas de ensino absorveram a matrícula nessa nova organização, pois, ao invés de uma implantação gradativa, o que se nota é a matrícula em massa, sem os ajustes pedagógicos e materiais necessários para isso, preconizados nos documentos, julgados adequados para um processo de inclusão 
pautado pelas premissas da qualidade da educação e universalização social. A Bahia implantou a nova política de organização do ensino em 2008, por meio da Resolução CEE nำ0 (BAHIA, 2007) e de dados coletados em pesquisa realizada na Bahia indicam:

[...] que os sistemas de ensino atentos ao prazo limite para a matrícula de todas as crianças de 6 anos no ensino obrigatório se preocuparam basicamente com os procedimentos de regulamentação da Lei 11.274/2006, sem fomentar ações de grande abrangência com a finalidade de qualificar profissionais para atuarem com as crianças, sem equipar e adequar as escolas de ensino fundamental para receber esse novo contingente $\mathrm{e}$ satisfazer as suas necessidades motoras, afetivas e cognitivas (SILVA, 2010, p. 97).

Assim, a matrícula das crianças se apresenta como o principal evento nesse período de quatro anos, até o prazo de 2010, desde a aprovação da Lei 11.274/06, para que todas elas estivessem devidamente inseridas nesse novo ordenamento. Isto deveria implicar ações indispensáveis para melhoria da qualidade das escolas em aspectos estruturantes e pedagógicos, no sentido de atender às particularidades das crianças de seis anos. Nesse aspecto, a política mostra-se frágil para criar as condições adequadas para promoção do acesso com qualidade, tanto em relação à infraestrutura, quanto à organização pedagógica.. (ASSIS, 2015)

O Ministério da Educação, por meio da Secretaria de Educação Básica (SEB) e do Departamento de Políticas de Educação Infantil e Ensino Fundamental, com vistas a favorecer o debate com professores e gestores sobre a criança e a educação - uma tentativa de minimizar as dificuldades da transição (do EF de oito para nove anos) - elaborou um documento (nove cadernos), cuja ênfase era o desenvolvimento e a aprendizagem das crianças de seis anos de idade:

\begin{abstract}
A infância e sua singularidade; $A$ infância na escola e na vida: uma relação fundamental; O brincar como um modo de ser e estar no mundo; As diversas expressões e o desenvolvimento da criança na escola; As crianças de seis anos e as áreas do conhecimento; Letramento e alfabetização: pensando a prática pedagógica; A organização do trabalho pedagógico: alfabetização e letramento como eixos orientadores; Avaliação e aprendizagem na escola: a prática pedagógica como eixo da reflexão; e Modalidades organizativas do trabalho pedagógico: uma possibilidade. (BRASIL, 2007, p.20).
\end{abstract}

Esse documento, publicado logo após a promulgação da Lei nํ. 11.274/06, intitulado: Ensino fundamental de nove anos: orientações para a inclusão da criança de seis anos de idade (Brasil, 2007) traz orientações para os sistemas ou redes de ensino realizarem a adequação do currículo escolar e oferecerem formação e 
diretrizes aos professores que trabalharão com as crianças de seis anos, considerando as especificidades e demandas desta idade, tendo em vista contemplar os propósitos do EF de nove anos.

Arelaro et al (2011, p.37) evidenciam que essa e outras iniciativas são importantes para a preparação das redes de ensino para a entrada da criança de seis anos. De acordo com os dados do $2^{\circ}$ Relatório para Ampliação do Ensino Fundamental do MEC:

Desses encontros participaram 247 secretarias de educação que, em 2003, haviam manifestado interesse na ampliação imediata: quatro estaduais Amazonas, Distrito Federal, Goiás e Sergipe - e 243 municipais. Participaram, ainda, dos encontros regionais representantes da União dos Dirigentes Municipais de Educação (UNDIME) e do Conselho Nacional de Educação (CNE), secretários estaduais e municipais de educação, equipes técnicas das secretarias de educação, diretores de escola, professores da Educação Infantil e do Ensino Fundamental, supervisores e inspetores de ensino, orientadores pedagógicos e outros profissionais da educação. (BRASIL, 2005, p. 04).

Dado que o Brasil tem 5.570 municípios, pode-se afirmar que o número de participantes é muito pequeno em termos representativos 4,44\%. De acordo com o documento, nove secretarias municipais de educação do estado de São Paulo participaram dos encontros. Como São Paulo tem 645 municípios, participaram apenas $1,4 \%$ dos órgãos municipais, e não os com maior densidade populacional. Caberia refletir sobre a pequena participação dos estados e municípios nesse processo e o impacto disto "no chão da escola", nas práticas educativas das escolas brasileiras frente ao novo ordenamento político. (ARELARO, 2011, p.41).

Sobre o trabalho com o corpo, objeto de estudo da pesquisa em questão, no Caderno Três de orientações do MEC, intitulado O brincar como modo de ser e estar no mundo, de autoria de Ângela Meyer Borba, é realizada uma abordagem que enfatiza o brincar como uma singularidade da criança e a importância de explorar essa atividade no currículo desta fase escolar:

Partindo do princípio de que o brincar é da natureza de ser criança, não
poderíamos deixar de assegurar um espaço privilegiado para o diálogo
sobre tal temática. Hoje, os profissionais da docência estão diante de uma
boa oportunidade de revisão da proposta pedagógica e do projeto
pedagógico da escola, pois chegaram, para compor essa trajetória de nove
anos de ensino e aprendizagens, crianças de seis anos que, por sua vez,
vão se encontrar com outras infâncias de sete, oito, nove e dez anos de
idade. Se assim entendermos, estaremos convencidos de que este é o
momento de recolocarmos no currículo dessa etapa da educação básica $O$
brincar como um modo de ser e estar no mundo; o brincar como uma das
prioridades de estudo nos espaços de debates pedagógicos, nos programas 
de formação continuada, nos tempos de planejamento. (BRASIL, 2007, p. 910 , grifo do autor).

Observa-se nesses preceitos a visão do brincar como uma possibilidade da educação continuada, dos espaços de discussões; o lúdico e o brincar são vistos como uma expressão de legitimidade da infância e princípio da prática pedagógica, como parte do processo de significação da aprendizagem, possibilidade de trabalhar com as crianças de maneira que sejam considerados suas individualidades e seu contexto de origem, seu desenvolvimento e o acesso aos conhecimentos. Portanto, compreender a importância das brincadeiras é assegurar a aprendizagem e o desenvolvimento total da criança. Para isso, é preciso desenvolver práticas pedagógicas que promovam o movimento corporal, a partir de jogos e brincadeiras, não o brincar por brincar, para assim atender às necessidades da criança de seis anos.

O brincar supõe, também, o aprendizado de uma forma particular de relação com o mundo, marcada pelo distanciamento da realidade da vida comum, ainda que nela referenciada. As brincadeiras de imaginação/fantasia, por exemplo, exigem que seus participantes compreendam que o que está se fazendo não é o que representa o real.

A brincadeira por isso está entre as atividades frequentemente avaliadas
por nós como tempo perdido. Por que isso ocorre? Ora, essa visão é fruto
da ideia de que a brincadeira é uma atividade oposta ao trabalho, sendo
menos importante, uma vez que não se vincula ao mundo produtivo, não
gera resultados. E é essa concepção que provoca a diminuição dos
espaços e tempos do brincar à medida que avançam as séries/anos do
ensino fundamental. Seu lugar e seu tempo vão se restringindo à "hora do
recreio", assumindo contornos cada vez mais definidos e restritos em
termos de horários, espaços e disciplina: não pode correr, pular, jogar bola
etc. (BRASIL, 2006, p.35, grifo do autor).

No Caderno Quatro das orientações, é discutida a importância das Diversas expressões e o desenvolvimento da criança na escola, por entender que, para favorecer a aprendizagem, é preciso dialogar com o ser humano em todas as suas dimensões (físicas, cognitivas e afetivo-sociais). Para tanto, a escola deve garantir tempos e espaços para o movimento, a dança, a música, a arte, o teatro:

\footnotetext{
Esse ser humano que carrega a leveza da infância ou a inquietude da adolescência precisa vivenciar, sentir, perceber a essência de cada uma das expressões que o tornam ainda mais humano. Portanto, é necessário rever o uso dessas expressões como pretexto para disciplinar o corpo, como, por exemplo, a utilização da música exclusivamente para anunciar a hora do lanche, da saída, de fazer silêncio, de aprender letras, de produzir textos, de ir ao banheiro [...]. (BRASIL, 2006, p.10).
} 
Ao compreender que a ação pedagógica, também, é atravessada por concepções que as professoras atribuem a determinado tema, o objeto desse artigo, incide sobre concepções ${ }^{4}$ de corpo, atribuídas pelas professoras que trabalham com crianças de seis anos. Pretende-se, assim, responder a seguintes questão: Como professoras do primeiro ano, do EF, significam o corpo?

Utilizou-se para a realização dessa pesquisa a abordagem qualitativa, cuja intenção é buscar "o que, na realidade, faz sentido e como faz sentido para os sujeitos investigados". (AMADO, 2017, p.43). Qualitativo:

[...] implica uma ênfase na qualidade das entidades estudadas e nos processos e significações que não são examináveis experimentalmente mensuráveis, em termos de quantidade, crescimento, intensidade ou frequência [...] os investigadores qualitativos realçam a natureza socialmente construída da realidade, a intima relação entre investigador e o que é estudado, e os constrangimentos situacionais que dão forma à investigação [...]. (DENZIN E LINCOLN, 2003, p.13 apud AMADO, 2017, p.42).

Ao buscar acessar concepção de corpo atribuída por professoras, a condição de investigadora qualitativa que tem experiência como professora e pesquisadora de práticas pedagógicas, nos anos iniciais colocou-nos diante do desafio de não nos tornarmos um duplo dos informantes e, por esta razão, escolhemos a entrevista semiestruturada, ainda que contenha alguma estrutura, como possibilidade de deixar os sujeitos mais livres para responder as questões e podermos acessar a subjetividade da relação entre pratica pedagógica e corpo, por entendermos que o modo como pensam a realidade interfere na conduta pedagógica. Foram entrevistadas 5 (cinco) professoras, as quais atribuímos o nome de Maria ${ }^{5}$ e identificamo-las pela numeração $(1,2,3,4,5)$, responsáveis pelas cinco turmas existentes, que se disponibilizaram a colaborar com a pesquisa, as quais apresentaremos no item "Motivações iniciais para ser professora e experiências formativas". As entrevistas foram realizadas na escola, no horário de reunião pedagógica, em um espaço reservado.

Para analisar os dados utilizou-se a análise de conteúdo a posteriori, com o objetivo de aproximar a análise, o máximo possível, do que foi dito pelos

\footnotetext{
${ }^{4} \mathrm{O}$ conceito de concepção aqui adotado nas palavras de Zabalza (apud AMADO, 2017, p. 43), "é aquilo que um professor, num dado momento, dá por assente e que orienta a sua ação, explicita ou explicitamente". Para Amado (2017) as concepções constituem um arcabouço mental que abarca conceitos anteriores e que propicia o entendimento de fenômenos cotidianos.

${ }^{5}$ Optamos por não identificar as informantes para evitar exposição, afinal trabalhamos na rede, na condição de professora e de coordenadora do PIBID.
} 
interlocutores. Numa primeira etapa foi realizada uma leitura vertical do material produzido e, em um segundo momento, a leitura horizontal, de modo a buscar aproximações e diferenças entre as concepções e que marcam a ação pedagógica. Como unidade de sentido escolheu-se a frase por permitir refinar o que define a concepção de corpo, de cada professora.

O campo empírico deste estudo foi uma escola do Ensino Fundamental ${ }^{6}$, de uma cidade do interior da Bahia. A se justifica por ser a maior escola do Município em atendimento a crianças do primeiro ano EF, totalizando 5 turmas, segundo dados da Secretaria Municipal de Educação (SMED) o que implica maior número de professoras nessa modalidade de ensino. Outro aspecto é o fato de a escola ser referência em EF de Nove Anos.

A escola foi fundada no dia 13 de março de 1997. Atende 1250 alunos, possui 91 funcionários, 17 professores de anos iniciais e 26 de anos finais, 1 diretora, 2 vice-diretoras, 2 articuladores do Projeto Mais Educação e 2 coordenadoras. Disponibiliza-se ali o Ensino Fundamental, do $1^{\circ}$ ao $9^{\circ}$ ano, divididos em ciclos $(6$ a

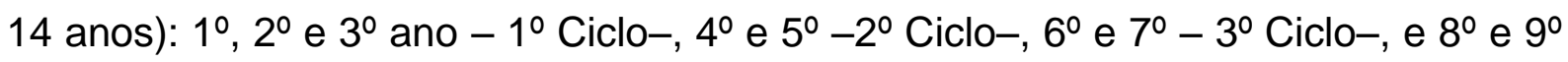
- 4 Ciclo. Vale lembrar que a escola atende ao período de implantação do EF de nove anos, ocorrido em 2010, prazo estipulado por meio da Resolução Conselho Estadual de Educação (CEE) nํ 60 (BAHIA, 2007), para a implantação do novo ordenamento jurídico administrativo. Trata-se de uma escola ampla, com pátio grande, quadra poliesportiva coberta e boa estrutura física para o desenvolvimento de atividades recreativas e físico-esportivas. Por conta disso, faz parte do projeto político pedagógico da escola o Programa Mais Educação, do Governo Federal, e o PIBID, Programa Institucional de Bolsa de Iniciação à Docência.

\section{MOTIVAÇÕES INICIAIS PARA SER PROFESSORA E EXPERIÊNCIAS FORMATIVAS}

Nesse item pretende-se apresentar as informantes no que se refere às subjetividades presentes nas motivações para ser professora e nas experiências formativas. Considera-se importante fazê-lo para situar o sujeito que fala. Sobre motivações para ser professora, Maria 1 afirma: [...]meu pai, ele tinha um grande

\footnotetext{
${ }^{6}$ Optamos por não identificar a escola para resguardar o anonimato.
} 
sonho de ter uma filha professora ${ }^{7}$; Maria 3 [...] desde pequena cresci vendo minhas tias preparando aulas, fazendo jogos, toda essa parte do lúdico, da decoração minha mãe era professora e minhas tias também; Maria 4: [...] às vezes a minha mãe falava, "vai ser professora", e aí fiz magistério e Maria 5: [...] minha família, minha mãe, ela me proporcionou, me ajudou a conseguir esse objetivo. A família é influenciadora das escolhas das professoras, o que revela que a socialização primária interfere diretamente nas escolhas profissionais, como resposta as expetativas dos pais e na interação com professoras na família que apresenta o magistério como uma profissão de valor afetivo e social.

Maria 5, além da influência familiar, tem admiração pela profissão: [...] quando eu via professores dando aula, eu vibrava. Então, assim, foi uma carreira que eu escolhi [...] Desde nova eu achava que o professor, ele era valorizado, ele era bem pago [...]. A admiração pela carreira docente nasce no que chamamos de socialização secundária, traduzida pela valorização do ser professora.

Sobre a valorização da docência, observa-se atualmente que:

\begin{abstract}
A diminuição da procura, por parte dos jovens, da profissão de professor tem-se tornado objeto de preocupação nos últimos anos. A falta de docentes bem formados e a escassez de profissionais para algumas áreas disciplinares dos últimos anos do ensino fundamental e ensino médio é discutida tanto em artigos acadêmicos como na mídia. Ao mesmo tempo, divulga-se não só a tendência de queda na demanda pelas licenciaturas e no número de formandos, mas também a mudança de perfil do público que busca a docência. (TARTUCE et. al, 2010, p. 446).
\end{abstract}

Percebemos nos depoimentos destas professoras que as escolhas dos indivíduos são condicionadas pelas relações com outros sujeitos: pai, mãe, tias, outros professores e valorização profissional (status), construídos na e pela relação com o outro. É o sentido de ser professora sendo construído no sentimento, no querer, no desejo de tornar-se professora. Sentimentos ancorados nas relações afetivas, que condicionam a escolha da profissão, na medida em que a identidade se afirma com o outro e pelo outro (CRUSOÉ, 2014).

Maria 2 assim diz: Não foi planejado, tudo aconteceu por acaso!; Maria 4: Na verdade, naquela época, há muito tempo atrás, não tinha tanta opção [...], as opções eram: magistério e contabilidade. Percebemos que, apesar de a trajetória escolar das professoras serem marcadas por um período de poucas opções profissionais, o

\footnotetext{
${ }^{7}$ Optamos por colocar a fala das entrevistadas em itálico para diferencias da fala dos autores e das pesquisadoras.
} 
curso de magistério representou para elas a alternativa mais atraente para continuar os estudos, dentre os cursos existentes na cidade em que residiam.

Nas palavras de Maria 1, além da influência do pai, conforme indicamos acima,: [...]eu acho gostoso você trabalhar em algo, sempre achei, que você pode movimentar o seu corpo, você tem liberdade para falar [...]. Ensinar implica liberdade em relação ao exercício da docência, a possibilidade de movimentar-se, de poder falar, durante a aula. Essa motivação indica que as escolhas são condicionadas pelos sentidos atribuídos ao exercício profissional, percebido por Maria 1, pela relação existente entre corpo e trabalho, e que influencia no processo de produção de sentidos de ser professora e estar professora. Sobre isso, Merleau-Ponty (/1999, p. 207-208) afirma que: "eu não estou diante do meu corpo, estou em meu corpo, ou antes, sou meu corpo". O eu se revela pelas manifestações corporais, gestos, ações o que possibilita a manifestação da unidade entre pensamento e ação, entre a dimensão física e psíquica.

Ao narrar sua trajetória de vida, as professoras atribuem sentidos à sua escolha profissional, permeados pelos sentidos dos outros, pois as escolhas são forjadas nas relações. O significado dado aos fatos narrados passa por escolhas valorativas, reveladas a partir de sentidos múltiplos, portanto, a realidade posta é reflexo disso. Nesse ir e vir, as educadoras tornam-se autoras e criadoras de sua trajetória de vida. Também, os motivos diversos e inclinações que levaram esse grupo de mulheres a ser professora implicam que as escolhas profissionais não são somente vinculadas à ideia de vocação, mas, também ligada à necessidade de ter uma profissão e cumprir uma trajetória escolar.

Fica evidente que fatores externos determinaram a escolha profissional: influência familiar, admiração pela profissão, status e relação corpo e trabalho, mas as experiências formativas e profissionais destas educadoras foram imprescindíveis para levá-las a gostar de ser professora e a permanecer no magistério. Os motivos revelaram que é mais do que gostar do que fazem, é sentirem-se motivadas ao fazer, ratificados no exercício profissional, Maria 1 diz: [...] Eu trabalhei numa zona rural na época, e lá na zona rural, aquela interação com os alunos me fez gostar ainda mais, e cada dia mais fui pegando gosto, pegando gosto, pela profissão. Não foi a tal da vocação como muita gente fala, né? Mas, foi algo foi mais forte que vocação [...]. 
Maria 4: [...] eu estava fazendo, eu amei a profissão, entendeu? E para Maria 2, que não possuía inclinações iniciais para o magistério, como as demais professoras (influência familiar, por exemplo), é motivada pela prática docente: [...] $E$ no decorrer da função, eu fui me apaixonando, tenho paixão por sala de aula até hoje! O fazer docente destas professoras tem uma forte relação com o gostar de dar aula, revelado desde a formação inicial no magistério. O sentido de gostar do que fazem aparece, mais de uma vez, como uma experiência marcada por satisfação e gosto pela profissão, construído ao longo dos anos e ressignificado na construção do sentido de ser professora.

Dentre as possibilidades que essas narrativas trazem, a ideia da consolidação da carreira (formação da identidade docente) do magistério no exercício docente está ligada às experiências formativas iniciais e motivações para ser professora. Maria 1, diz: [...]o curso de magistério ele nos preparava de maneiras, assim, bem fiel, [...] preparava todo o material para o estágio. Aprende-se, na formação, a preparar a aula e a gostar de ministra-la. Percebe-se que esse sentido é construído ao longo das atividades de estágio, ainda no curso de magistério como discente, nas experiências formativas, juntamente com professores de estágio, estudantes, colegas e outros sujeitos.

As motivações iniciais para ser professora e as experiências formativas partiram de diferentes pontos: influência da família, admiração, gosto pela profissão, valorização profissional e da relação corpo e trabalho. Existe entre as professoras uma escolha profissional em comum que não é dada a princípio, mas que é construída na interseção de concepções construídas nas relações e interações sociais, adquiridas de forma espontânea ao longo da sua trajetória de vida e consolidada no exercício da docência.

\section{SOBRE CORPO, O QUE PENSAM AS PROFESSORAS}

Sobre corpo e prática pedagógica, Maria 1 afirma que é: [...]a morada do Espírito Santo. Para Maria 2: Criação divina, é isso, perfeita, perfeita! E, para Maria 5: [...] é uma coisa linda que Deus criou [...]. Essa concepção de corpo voltada para a dimensão religiosa, segundo Assmann (1995), está relacionada aos dogmas religiosos que impõem ao corpo o significado de morada, de templo sagrado. Não 
obstante, essa concepção é ancorada, também, na formação jesuítica da escola brasileira e na religiosidade do próprio povo. Pode-se dizer que a religião é intrínseca ao povo brasileiro ainda que a escola seja um campo de educação formal e laico, nela, também, estão presentes estratégias, conteúdos educativos e interrelações diversas, presentes nas práticas educativas em sala de aula que caracterizam a transmissão de conhecimento informal e subjetivo (valores religiosos), que, nas palavras de Sacristán (2000), seria o currículo oculto, uma vez que a religiosidade é uma dimensão da identidade dos sujeitos, que compõem a escola.

O discurso de Maria 1 é de que [...] corpo e alma têm que andar de braços juntos, a minha alma tem que estar feliz, meu corpo precisa estar feliz [...] e, para Maria 5, O corpo é uma estrutura que o ser humano deve estar trabalhando como um todo: o físico, a mente e o espírito!. A fala das duas professoras traz a concepção da necessidade da união e do equilíbrio entre: corpo e alma, corpo e mente, corpo e espírito, divergente da concepção platônica. Para Platão (1979), há no homem um dualismo, ele seria constituído por duas naturezas distintas: pela alma e pelo corpo. A alma é a parte divina, imortal, pois está ligada ao bem, à verdade essencial, ao passo que o corpo é a parte considerada inferior do homem, pois é a sepultura da alma, sua prisão, sua mortalha. De acordo com a filosofia platônica, para contemplar as verdadeiras ideias, a alma deve rejeitar a associação com o corpo durante toda a existência. Só assim, será possível à alma atingir a plenitude. "Em resumo, o corpo é um 'inimigo' que devemos vigiar sem cessar. Trata-se de um 'intrujão', um déspota que temos de controlar incansavelmente para que não nos afaste do caminho da perfeição" (BARRENECHEA, 2002, p. 179, grifo do autor). Essa concepção dualista, permanece na Idade Média, as dicotomias foram intensas nesse período, tais como o bem e o mal, o sagrado e o profano. 0 homem ficou dividido, o ser era formado de carne e espírito. De um lado a alma, imortal, que aspira à perfeição celeste, e do outro lado o corpo, mortal, perecível.

As concepções de corpo, reveladas pelas narrativas, demonstram uma superação dessa visão fragmentada do homem, presente na visão platônica e na idade média, ou seja, as professoras percebem a importância do equilíbrio das dimensões em que o corpo está inscrito. 
Maria 2 assim diz: [...] corpo é um conjunto de órgãos harmonizados perfeitamente [...]. Nas palavras de Maria 3: Eu vejo o corpo como o nosso corpo físico [...], e, na fala Maria 4: Eu acho que corpo é vida [...]. As concepções presentes nessas narrativas tratam o corpo, pelo viés biológico. Para Maria 1: [...] é toda carga genética que trouxe desde o ventre da minha mãe, tudo que passei durante os longos anos que vivi e até hoje aonde cheguei [...]. O ensino de Biologia nas universidades e escolas ratificam, de certa forma, essas versões científicas do corpo e, no caso do curso de pedagogia, área de formação das professoras entrevistadas, discussões sobre corpo quase não aparecem nas disciplinas de metodologias de ensino e outras. No caso da educação escolarizada, as pedagogias empregadas no estudo do corpo humano, ao tomarem como referência as disciplinas acadêmicas, vêm afirmar o corpo como mera descrição anatômica, fisiológica, morfológica e metabólica (TRIVELATO, 2011).

Esse discurso proveniente da visão mecanicista sobre seres vivos, vem reduzindo o corpo aos seus constituintes e à categoria biológica. Tal maneira de pensar, conhecer, nomear e explicar o corpo humano, presente no discurso científico, tem produzido formas fragmentadas de pensar em relação à sua constituição, ao seu funcionamento e aos processos que nele ocorrem como, também, formas desvinculadas das suas inter-relações com as condições históricas, ambientais e culturais, em que o corpo humano se encontra relacionado. Ou seja, como um organismo atemporal e universal sem relação com os acontecimentos que o configuram cotidianamente e o posicionam como dotado de individualidades. Nessa óptica, desconhece-se que:

[...] ele é formado por uma série de regimes que o constroem; ele é destroçado por ritmos de trabalho, repouso e festa; ele é intoxicado por venenos (alimentos ou valores, hábitos alimentares e leis morais simultaneamente); ele cria resistências. (FOUCAULT, 1998, p. 27).

No corpo e em todo o conjunto de práticas e técnicas corporais estão implícitos valores sociais, culturais, políticos e econômicos do contexto histórico que perpassa o percurso humano na sociedade. Neste tocante, são nas diversas relações existentes nas práticas pedagógicas dessas professoras que se configuram os principais elementos para entendimento das concepções imputadas ao corpo, visto que tais concepções sofrem influências externas da cultura de maneira geral, mas, também, da própria instituição escolar. 
A concepção voltada para valorização da aparência física aparece, também, no discurso de Maria 1: [...] como você se olha, como você se vê, como você se veste, como você anda, [...]; [...] mais o seu estilo de vida, sua maneira de viver, de cuidar do seu corpo[...]. Essas narrativas têm ancoragem nas análises de Foucault (2014), observadas no contexto do século XX, em que indivíduos são incentivados a manter formas corporais padronizadas, corpo consumo. Há, com isso, a garantia do surgimento contínuo de novas demandas de consumo e novos mercados: cosméticos e fármacos para combater os sinais do tempo, alimentos diet, light, academias de ginástica, cirurgias plásticas, dentre outros, para uma determinada classe. Com vistas ao alcance de corpos saudáveis e em boa forma física, por meio de um estilo de vida e do desejo de obter a perfeição corporal, levou-se o homem do século XX e XXI a buscar, excessivamente, um novo padrão de beleza, na tentativa de satisfazer uma exigência para a sua inclusão na sociedade. Aqueles que se recusam ou que se veem impossibilitados de participar desse esforço pela boa forma são, muitas vezes, submetidos a estigmas que reforçam um sistema de poder sobre o corpo. (FOUCAULT, 2014).

Para a professora Maria 4, Nós somos o corpo, e aí tudo que você pensa, que você faz é o seu corpo[...]. Segundo Maria 1, [...] o corpo, também, é o acarretamento de tudo que eu vivi até aqui [...]. De acordo com as professoras, o corpo revela nossa unidade de existência, nos dá visibilidade e acesso ao mundo. É interpretado como marca da existência humana, no mundo da vida e indica uma superação no modo de compreender o ser humano, contém a concepção de corpo como conjunto de situações individuais e coletivas que determinam um sujeito único, pois as experiências podem ser coletivas, mas trazem percepções e sentidos únicos a cada sujeito. (MERLEAU-PONTY,1999).

As concepções atribuídas ao corpo, pelas professoras do primeiro ano do EF (corpo divino, corpo físico (biológico), estilo de vida (corpo consumo) o corpo unido e corpo vivido, são múltiplas, temporais, convergentes e divergentes ao mesmo tempo, ora considerando-o em sua totalidade, corpo vivido, ora como corpo físico, destituído de influencias das experiências corporais, do seu contexto de vida; ora considerando-o como corpo divino, ligado a esfera religiosa e ao estilo de vida, corpo consumo. Essas diferentes concepções, presente nas narrativas das educadoras, refletem contradições no discurso sobre o corpóreo, socialmente 
estabelecidos e codificados nas relações e, portanto, significados e ressignificados no contexto escolar. Entendemos que essas relações são, acima de tudo, corporais; há um nível de compreensão que transcende a dimensão cognitiva, a interpretação consciente ou a abstração, que passa pela relação estabelecida pelos sujeitos em sua vivência enquanto sujeitos no mundo. E essa relação é, primeiramente, uma relação corpórea. (MERLEAU-PONTY, 1999).

Sobre a relação do corpo e aprendizagem, para Maria 1: [...] quando ele não está "presente", a gente só tem o corpo, mas a alma está longe, ele está muito distante, ele não está prestando atenção, ou ele não está aprendendo [...], ou seja, o aluno quando não está atento em sala de aula, está ausente, pois o corpo está presente, mas o pensamento não. Maria 4 aponta: $O$ corpo tem que estar bem, para que a mente possa trabalhar também! $O$ corpo do aluno é essencial para 0 aprendizado, em sala de aula.

Para Maria 2, [...] se não tiver essa harmonia entre os órgãos, ou seja, se não estiver saudável, mente e corpo, interfere sim na aprendizagem! A concepção dada à relação corpo e aprendizagem, assim revelado pela professora, com ênfase na condição de saúde do corpo físico, remete-nos a relação da saúde com a aprendizagem, presente nos encaminhamentos médicos e repercussão no sistema escolar na atualidade. As orientações médicas são atuantes em nossos dias, devido à frequência da busca de recursos terapêuticos no campo da saúde, por parte dos educadores, para solucionar dificuldades encontradas no processo pedagógico (dificuldade de aprendizagem, comportamento indisciplinado, apatia, entre outros), sobretudo no EF, e nas respostas de psicólogos e médicos a esta demanda escolar. (BOARINI, 2006).

$\mathrm{Na}$ atualidade, percebe-se o corpo de variadas ópticas, sob diferentes abordagens e concepções teóricas. Nesse tocante, as concepções atribuídas à relação corpo e aprendizagem, por Maria 1, por exemplo, transitam entre essa diversidade de atributos advindos da cultura, da sua história de vida e formação acadêmica, ressignificados na prática educativa na escola, ora considerando o corpo fragmentado, ora em sua totalidade: [...] corpo e aprendizagem estão intimamente ligados, o corpo e a aprendizagem, já que o sujeito é único [...] (MARIA 1); o significado dado ao corpo implica identidade, unidade de existência, integralidade e, por conseguinte, visibilidade, acesso ao mundo. Maria 3 entende que: [...] não dá 
para separar a aprendizagem do corpo, não tem como não relacionar o corpo com a aprendizagem [...]. Essas narrativas convergem para a concepção dada à relação corpo e aprendizagem em que a experiência da vivência corporal é fundamental para a aprendizagem significativa:

O que é imediatamente experimentado não precisa ser ensinado nem repetido para ser memorizado [...] aprendizagem imediata. Quanto mais separado da experiência um determinado conteúdo estiver, maiores e mais complicadas as mediações verbais. (ALVES, 1998, p. 46).

Percebemos que essa visão retrata a educação pelo movimento, para o movimento, na medida em que valoriza a sinestesia nas práticas educativas para que a aprendizagem seja dotada de sentido. A partir disso, entendemos que essas educadoras compreendem a criança como ser integral, nas suas possibilidades de conviver e viver experiências para a compreensão do mundo a partir da totalidade dos seus sentidos, "no conhecimento que constrói na relação intrínseca entre razão e emoção, expressão corporal e verbal, experimentação prática e elaboração conceitual". (BRASIL, 2013, p.89). Os documentos para a inserção da criança de seis anos no Ensino Fundamental afirmam que a aprendizagem, no primeiro ano EF, deve ser significativa, prazerosa, dotada se sentido, "ao reconhecer as crianças como seres íntegros que aprendem a ser e a conviver consigo mesmas, com os demais e com o meio ambiente de maneira articulada e gradual [...]". (BRASIL, 2005, p.15).

Quanto a concepção de corpo/movimento, para Maria 3: [...] nos anos iniciais, ao introduzir qualquer assunto, a gente sempre começa com a psicomotricidade.É conhecendo o corpo que a criança, ela vai, ela vai se despertando para a vida [...].Para Maria 5: [...] A partir da movimentação em sala, quando eu digo esquerda e direita, direita e esquerda, movimentando o corpo, ele aprende, com muito mais facilidade [...].Observa-se que o movimento corporal aparece nas duas assertivas, 0 que significa compreender o indivíduo pelo viés da psicomotricidade, como um ser social, afetivo e físico, em constante modificação; da existência de uma intencionalidade (ações em direção a algo que se deseja), de uma motricidade que nos coloca em ação no mundo, pois o desenvolvimento humano é fruto de experiências em todas as fases da vida, num processo que se inicia desde a fase intrauterina. (LE BOULCH, 2001; PIAGET, 2007). 
Maria 5 exemplifica que [...] quando você trabalha a música, quando você trabalha uma arte, então, você está trabalhando com o corpo. Ou seja, o sujeito se constrói com base em suas experiências com o meio durante a infância, tornando a educação psicomotora indispensável na formação de base, "[...] leva a criança a tomar consciência de seu corpo, da lateralidade, a situação no espaço, a dominar seu tempo, a adquirir habilidades de coordenação de seus gestos e movimentos [...]" (LE BOULCH, 2001, p. 24), já que dá condições para ela interagir com o ambiente, ajudando-a a se adaptar e a superar possíveis problemas.

Outros aspectos podem ser pensados sobre a relação corpo e aprendizagem, para além dos elencados nas narrativas: visão dicotômica, corpo e movimento e corpo pelo viés psicomotor, mas nenhum deles a encerra, define, circunscreve, pois, o corpo escapa a qualquer moldura, a qualquer circunferência e "não explica a si mesmo [...] não é um dado inequívoco, mas o efeito de uma elaboração social e cultural [...]". (LE BRETON, 2007, p. 26).

\section{CONSIDERAÇÕES FINAIS}

Retomamos aqui a questão de pesquisa: Como professoras do primeiro ano, do EF, significam o corpo? Dentre os achados temos: corpo divino, corpo físico (biológico), corpo consumo (estilo de vida/estética), o corpo unido, corpo vivido, corpo e alma (visão dicotômica), corpo e movimento (psicomotor) o que revela, ainda hoje, que

[...] as teorias educacionais e as inúmeras disciplinas que constituem os cursos de formação docente pouco ou nada nos dizem sobre os corpos dos estudantes ou dos nossos. Com exceção da Educação Física, que faz do corpo e de seu adestramento o foco central de seu agir, todas as demais áreas ou disciplinas parecem ter conseguido produzir seu "corpo de conhecimento" sem o corpo. No "sagrado" campo da educação não apenas separamos mente e corpo, mas, mais do que isso, suspeitamos do corpo. Aparentemente estamos, nas escolas e universidades, lidando exclusivamente com ideias e conceitos que de algum modo fluem de seres incorpóreos. (LOURO, 2000, p.2).

Revelam dimensões psicológica, biológica e social sem, contudo, atrelar ás

questões culturais, econômicas e históricas o que dificulta a assunção do corpo como identidade, por parte das crianças.

$\mathrm{Na}$ tradição dualista, que se mantém e se multiplica em inúmeras polaridades, natureza e cultura estão separadas; o corpo, localizado no âmbito da natureza, é negado na instância da cultura. Na concepção de muitos, o corpo é "dado" ao nascer; ele é um legado que carrega "naturalmente" certas características, que traz uma determinada forma, que 
possui algumas "marcas" distintivas. Para outros, no entanto, é impossível separar as duas dimensões. Nessa perspectiva, o corpo não é "dado", mas sim produzido - cultural e discursivamente - e, nesse processo, ele adquire as "marcas" da cultura, tornando-se distinto. As formas de intervir nos corpos - ou de reconhecer a intervenção - irão variar conforme a perspectiva assumida. llusório será acreditar, contudo, que, em algum momento, as instâncias pedagógicas deixaram de se ocupar e se preocupar com eles. (LOURO, 2000, p.3).

Nos contornos dessa pesquisa, nos preocupamos com a formulação e circulação desse discurso nos currículos e nas práticas pedagógicas. O desafio que se nos impõe, na condição de professores e pesquisadores, é de observar como tais discursos se apresentam no currículo oculto, se desviam e se deslocam na ação pedagógica com vistas a estabelecer uma pratica pedagógica para as diferenças de gênero, raça e sexualidade, por exemplo, em que se valorize as identidades, com toda a pluralidade em que se apresenta a criança de seis anos, nas escolas de EF. 


\section{REFERÊNCIAS}

ALVES, Rubem. Conversas com quem gosta de ensinar. 22. ed. São Paulo: Cortez, 1988.

AMADO, João, (org.). Manual de investigação qualitativa em educação. 2. ed. Coimbra: Imprensa da Universidade de Coimbra, 2017.

ARELARO, Lisete R. Gomes; JACOMINI, Marcia Aparecida; Klein, Syvie Bonifácio. 0 ensino fundamental de nove anos e o direito à educação. Educação e Pesquisa, São Paulo, v.37, n.1, 220p. 35-51, jan./abr. 2011. Disponível em: < https://www.scielo.br/pdf/ep/v37n1/v37n1a03.pdf > Acesso em: 6 out. 2020.

ASSIS, Lidiane Souza de. As crianças de seis anos no ensino fundamental: implicações na organização do trabalho pedagógico de escolas municipais de Conceição do Jacuípe (2007-2012). 2015. 128f. Dissertação (Mestrado em Educação) - Programa de Pós-Graduação em Educação, Universidade Estadual de Feira de Santana, Bahia, 2015.

ASSMANN, H. Paradigmas educacionais e corporeidade. 3. ed. Piracicaba: Unimep, 1995.

BAHIA. Conselho Estadual de Educação. RESOLUÇÃo CEE №. 60, DE 5 DE JUNHO DE 2007. Disponível em: < http://www.conselhodeeducacao.ba.gov.br/arquivos/File/Resolucao CEE N 60200 7 e Parecer CEE N 187 2007.pdf > Acesso em: 6 out. 2020.

BARRENECHEA, Miguel Angel. Nietzsche e o corpo: para além do materialismo e do idealismo. In: Nietzsche e Deleuze: que pode o corpo. Rio de Janeiro: RelumeDumará, 2002.

BOARINI, Maria Lucia. O higienismo na educação escolar. In: VI CONGRESSO LUSO BRASILEIRO DE HISTÓRIA DA EDUCAÇÃO, 2006. 
BRASIL. Departamento de Políticas de Educação Infantil e Ensino Fundamental. Coordenação Geral do Ensino Fundamental. ENSINO FUNDAMENTAL DE NOVE ANOS - ORIENTAÇÕES GERAIS. Brasília: MEC, SEB, DPE, COEF, 2005.

Ampliação do Ensino Fundamental para Nove Anos - 3ª Edição / Ministério da Educação. Secretaria de Educação Básica. Departamento de Políticas de Educação Infantil e Ensino Fundamental. Coordenação Geral do Ensino Fundamental. Brasília: MEC, SEB, DPE, COEF, 2006.

Ensino fundamental de nove anos: orientações para a inclusão da criança de seis anos de idade. Organização de Jeanete Beauchamp, Sandra Denise Pagel, Aricélia Ribeiro do Nascimento. Brasília: Ministério da Educação, Secretaria de Educação Básica, 2007.

CRUSOÉ, Nilma Margarida de Castro. Prática pedagógica interdisciplinar na escola fundamental: sentidos atribuídos pelas professoras. Curitiba, PR, CRV, 2014.

FOUCAULT, Michel. Microfísica do poder. 2. ed. Rio de Janeiro: Graal, 1998.

LE BOULCH, J. O desenvolvimento psicomotor do nascimento até 6 anos. Porto Alegre: Artes Médicas; 2001.

LOURO, Guacira Lopes. Corpo, Escola e Identidade. Revista Educação e Realidade, Rio Grande do Sul, v.25. n.2, p. 1-17, julh-dez, 2000. Disponível em < https://seer.ufrgs.br/educacaoerealidade/article/view/46833/29119>. Acesso em: 5 out. 2020.

MERLEAU-PONTY. Maurice. Fenomenologia da percepção. 2. ed. São Paulo: Martins Fontes, 1999.

OLIVEIRA, Daniele Ramos de. A centralidade das atividades de alfabetização nas práticas pedagógicas do $1^{\circ}$ ano do ensino fundamental de nove anos: desafio a formação continuada. In: SEMINÁRIO DE PESQUISA EM EDUCAÇÃO DA REGIÃO SUL (ANPEDSUL), VIII, 2010. Anais... Londrina: UEL, 2010. CD-ROOM.

PLATÃO. Vida e obra. 2. ed. São Paulo: Abril Cultural, 1979.

SACRISTÁN, J. Gimeno. O Currículo: uma reflexão sobre a Prática. 3.ed. Porto Alegre: Artmed, 2000.

SILVA, Antonio Almeida. Ensino Fundamental de Nove Anos: política de integração de conformação social ?. Práxis Educativa, Ponta Grossa, v.5, n.1, p. 97-107, jan.jun. 2010. Disponível em <http://www.periodicos.uepg.br>. Acesso em: 11 mai. 2016.

TARTUCE, Gisela Lobo B. P.; NUNES, Marina M. R.; ALMEIDA. Alunos do ensino médio e atratividade da carreira docente no Brasil. Cad. Pesqui. [online]. 2010, vol.40, n.140, pp.445-477. Disponível em: < 
Concepções atribuídas ao corpo pelas professoras...

http://publicacoes.fcc.org.br/ojs/index.php/cp/article/view/172/185 > Acesso em: 6 out. 2020.

TRIVELATO, S. Que corpo/ser humano habita nossas escolas? In: MARANDINO, M. SELLES, S. E. FERREIRA M. S. Ensino de Biologia: histórias e práticas em diferentes espaços educativos. 1. ed. São Paulo: Cortez Editora, 2011. 